\title{
Narrative review of management controversies for paraesophageal hernia
}

\author{
Michael P. Rogers, Vic Velanovich, Christopher DuCoin \\ Division of Gastrointestinal Surgery, Department of Surgery, the University of South Florida, Tampa, Florida, USA \\ Contributions: (I) Conception and design: All authors; (II) Administrative support: None; (III) Provision of study materials or patients: None; (IV) \\ Collection and assembly of data: MP Rogers, V Velanovich; (V) Data analysis and interpretation: All authors; (VI) Manuscript writing: All authors; \\ (VII) Final approval of manuscript: All authors. \\ Correspondence to: Michael P. Rogers, MD, MS. Department of Surgery, University of South Florida Morsani College of Medicine, Tampa, FL, USA. \\ Email: Mrogers6@usf.edu.
}

\begin{abstract}
Objective: To review management controversies in paraesophageal hernia and options for surgical repair. Background: Paraesophageal hernia is an increasingly common problem. There are controversies over whether and when paraesophageal hernias should be surgically repaired. In addition, if these hernias are to be repaired, the method of repair, need for mesh reinforcement, need for fundoplication, and need for gastropexy are not uniformly accepted.

Methods: Recent literature was reviewed on need for repair, approach (open, laparoscopic or robotic surgery), method of repair (primary suture, use of relaxing incisions, use of mesh reinforcement), materials and configuration of mesh reinforcement, need and type of fundoplication, and need for gastropexy, with emphasis on surgical outcomes.

Conclusions: The extant literature suggests that paraesophageal hernia should be approached in a patient-centered, precision medicine manner. In general, hernia reduction, sac excision and primary suture approximation of the hiatal crura are mandatory. Use of mesh should be based on individual risk factors; if mesh is used, biological meshes appear to have a more favorable safety profile, with the "reverse C" or keyhole configuration allowing for increase in crural tensile strength at it most vulnerable areas. Use and choice of fundoplication or magnetic sphincter augmentation should be based on individual considerations. Finally, gastropexy is generally ineffective and should be used only in extreme circumstances.
\end{abstract}

Keywords: Paraesophageal hernia; esophageal hiatus; foregut; fundoplication

Submitted Apr 23, 2021. Accepted for publication Jun 11, 2021.

doi: $10.21037 /$ jtd-21-720

View this article at: https://dx.doi.org/10.21037/jtd-21-720

\section{Introduction}

\section{Rationale/background}

Hiatal hernia is a condition in which a portion of the stomach and other abdominal organs may herniate cephalad through the diaphragmatic hiatus into the mediastinum. This is often the result of widening of the diaphragmatic esophageal hiatus and weakening of the phrenoesophageal membrane. The true incidence of hiatal hernia in the general population is largely unknown as many patients are asymptomatic and may receive a diagnosis incidentally while undergoing imaging for chest or abdominal pain, or in the evaluation of unrelated conditions. Patients with symptoms may present with a wide range of complaints including chest or abdominal pain, dyspnea, or reflux, with the potential for life threatening complications including volvulus, incarceration, strangulation, or perforation. Hiatal hernias are categorized into four types:

* Type I: the gastroesophageal junction (GEJ) migrates above the diaphragm ("sliding type") due to circumferential laxity of the phrenoesophageal membrane and widening of the hiatus. 
* Type II: the GEJ remains in the normal anatomic position, with a portion of the fundus herniated through the hiatus alongside the esophagus.

* Type III: contains elements of Type I and II. The gastroesophageal junction is above the hiatus along with a portion of the stomach.

* Type IV: an intraabdominal organ, such as the colon, spleen, pancreas, and small intestine is additionally herniated through the hiatus

Type I hiatal hernias account for over $95 \%$ of the total prevalence (1). Type II-IV hernias together are referred to as paraesophageal hernias $(\mathrm{PEH})$ and differ from Type I by the preservation of posterolateral phrenoesopageal attachments at the GEJ. Type III hernias represent approximately $90 \%$ of $\mathrm{PEH}$, while types II and IV represent the remaining PEH's. Treatment of the three types of PEH's will be the focus of this review.

\section{Objectives}

Our objectives are to determine which patients require surgical repair. If surgical repaired is required, assessments of type of repair, use of mesh, use of fundoplication or magnetic sphincter augmentation, and use of gastropexy.

We present the following article in accordance with the Narrative Review reporting checklist (available at https:// dx.doi.org/10.21037/jtd-21-720).

\section{Methods}

A comprehensive review of the available current literature was performed on April 11, 2021, using PubMed, Cochrane Review, and the Society of American Gastrointestinal and Endoscopic Surgeons (SAGES) guidelines. Search terms included the following: "hiatal hernia" AND "repair" AND "fundoplication" AND "mesh". Available results were manually reviewed thoroughly for relevance and included (I) need for repair, (II) surgical approach (open, laparoscopic, or robotic surgery), (III) method of repair (primary suture, use of relaxing incisions, use of mesh reinforcement), (IV) materials and configuration of mesh reinforcement, (V) need and type of fundoplication, (VI) and need for gastropexy, with emphasis on surgical outcomes.

\section{Discussion}

\section{Indications for surgical repair}

Traditionally, surgical repair has been indicated for all patients presenting with paraesophageal hernia. Recently, however, non-surgical management has gained favor in asymptomatic and minimally symptomatic patients, especially in those with increased age or significant comorbidities. Contemporary analyses suggest completely asymptomatic paraesophageal hernias may be safe to observe and manage expectantly (2). Currently, it is recommended all symptomatic paraesophageal hiatal hernias be repaired, particularly those with acute obstructive symptoms or those presenting with volvulus $(3,4)$.

Patients presenting with symptoms including regurgitation, dyspnea, heartburn, chest or epigastric pain, dysphagia, emesis, weight loss, or anemia (secondary to a Cameron lesion) should be considered for elective operative repair. Those with acute gastric volvulus with resultant strangulation, ischemia, and perforation may require reduction of the stomach with limited resection, if indicated.

\section{Operative technical considerations}

Conventionally, paraesophageal hernia repair was approached by either laparotomy or thoracotomy. The morbidity associated with these approaches has driven innovative minimally invasive techniques. Contemporarily, paraesophageal hernia repair is performed laparoscopically or robotically with markedly improved post-operative outcomes, and thus has become the recommended operative approach $(5,6)$. While the transthoracic approach has been lauded for its ability to provide extensive esophageal mobilization, the morbidity of the procedure has essentially rendered this approach obsolete in modern practice. Further, many transthoracic series have cited an increased risk of requiring Collis gastroplasty for esophageal lengthening compared to laparoscopic series $(7,8)$. A laparoscopic approach is associated with less post-operative pain, smaller incisions, decreased risk of wound infection and incisional hernia, decreased postoperative respiratory complications, and shorter length of stay $(5,8-10)$. Recurrence rates, however, are similar between approaches. Recently, robotic-assisted approaches have gained popularity for their potential advantages over traditional laparoscopy, including enhanced visualization, improved ergonomics, and wristed articulating instruments (11). Recent analyses suggest a similar length of stay, operative times, and outcomes as compared to traditional laparoscopy (11-13).

\section{Need for hernia sac reduction}

Dissection of the hernia sac is thought to release the 
tethering of the esophagus and allow for complete reduction of the hernia, as well protect the esophagus from iatrogenic damage (14). Once dissection is achieved, complete hernia sac reduction from the mediastinum is recommended and routinely performed in recent series $(15,16)$. Existing literature largely supports this practice with hernia recurrence rates noted to be increased in those without sac reduction compared to those undergoing complete reduction.

Occasionally, hernia sac reduction from the mediastinum may be quite difficult due to a large paraesophageal hernia or re-operative surgery. In this circumstance, the hernia sac may be dissected from the crura and not completely resected as to decrease the risk of potential vagal nerve injury. Retrospective review has suggested this practice may be associated with a trend toward higher recurrence, however this was not statistically significant (17). The authors advocate for complete hernia sac reduction when able. Hernia sac excision is performed only if the resultant sac interferes with visualization or fundoplication construction. Alternatively, a partial excision is preferred when complete reduction is not possible to allow for an appropriate fundoplication to be performed without excessive residual tissue caused by a large hernia sac.

\section{Repair of the hiatal defect}

Primary suture approximation of the hiatus has remained the mainstay practice for years. However, it is noted there are high recurrence rates following laparoscopic paraesophageal hernia repair (18). Several hypotheses contributing to crural failure have been proposed and include the inability to achieve a tension free repair, failure to mobilize the appropriate length of esophagus, and lack of tendon reinforcement of the crura (19). At the hiatus, tension may occur secondary to a large hiatal defect resulting in splayed crura upon repair. This axial tension related lateral tension related to the widely splayed crura have been highlighted as potential improvement areas. Accordingly, efforts have focused on diaphragmatic relaxing incisions in an attempt to mitigate crural tension. Small series have demonstrated good short-term outcomes in patients with large paraesophageal hernias with no major complications $(20,21)$. When a relaxing incision is deemed necessary due to anticipated tension, the authors prefer a right-sided diaphragmatic incision as this is generally the easiest to perform, protected from recurrent herniation by the liver, and away from the phrenic bundle. This relaxing incision is then covered with biologic mesh. The mesh repair not only covers the defected created from the diaphragm release but helps reinforce the entirety of the repair as these releases are usually done for larger defects. If the right sided incision is inadequate or cannot be performed due to a thin right crura, a left sided diaphragmatic incision may be used, with care to avoid damage to the phrenic nerve in either case.

We also routinely perform an intra-operative flexible upper endoscopy to ensure at least $3 \mathrm{~cm}$ of esophageal mobilization was achieved below the diaphragm. This also serves as an appropriate sized bougie. Because PEH failure may be most commonly related to a short esophagus, this practice allows for the assessment of need for a Collis gastroplasty after sufficient mediastinal esophageal mobilization. It should be noted, however, that despite a high anatomic recurrence rate, symptomatic failure requiring surgical re-intervention remains low, at approximately $3 \%$ (22). The authors will consent a patient for a possible Collis gastroplasty when on the pre-operative EGD the GEJ is noted to be $\leq 35 \mathrm{~cm}$ from the incisors. Due to the ease and risk profile, a wedge Collis gastroplasty is to preferred option of choice. This is done after a complete mediastinal dissection has occurred, and the GEJ remains at the level of the hiatus or within the chest with the esophagus off tension.

\section{Use of mesh}

The use of mesh for paraesophageal hernia repair to reduce the incidence of recurrence remains an area of significant controversy. The basis of support stems from the observation of success in the repair of other hernias. The tension at the crural suture line or persistent transdiaphragmatic pressure is thought to lead to recurrence, whereas mesh may lead to increased tensile strength (23). Consequently, the routine use of mesh in crural repair has been an area of significant investigation.

Three randomized-controlled trials have evaluated the benefits of crural mesh repair. The first two reported significant reduction in recurrence rates during the study period using synthetic polytetrafluoroethylene (PTFE) mesh in an onlay fashion $(24,25)$. Frantzides and colleagues evaluated patients with large hiatal defects $(>8 \mathrm{~cm})$ with a mean follow-up of 3.3 years. Radiographic recurrence was reported at $22 \%$ in the primary suture repair group and all occurred within the first six months after repair, with no recurrence in the mesh cohort (24). While not specifically addressing hiatal hernias, the second randomized studied by Granderath and colleagues' analyzed patients that 
underwent complete hiatal esophageal mobilization during laparoscopic Nissen fundoplication and included approximately half of patients studied with hiatal defects $>5$ centimeters. PTFE was used in an onlay fashion with a reported $26 \%$ recurrence in those undergoing primary crural repair compared to $8 \%$ in those receiving mesh (25). The third randomized trial included $90 \%$ Type III and IV hiatal hernias in the control arm $(84 \%$ in the treatment arm) and demonstrated a significant reduction in 6-month recurrence rates between patients undergoing repair with porcine intestinal submucosal biologic mesh in a U-shaped fashion versus primary suture repair (9\% vs. 24\%, $\mathrm{P}=0.04)$, however reported equal recurrence rates and no difference in clinical symptoms at 4-year follow-up ( $>50 \%$ recurrence in both groups) (26). Of note, the drop-out rate during follow-up in this study was significant, with not all patients undergoing radiographic evaluation for recurrence.

Short term results of the available literature support mesh reinforcement in hiatal hernia repair; however, these results have not been observed long-term. Currently, there is insufficient long-term evidence to recommend for or against routine reinforcement with mesh at the hiatus. The authors recommend a tailored patient-specific approach, with mesh placement limited to those hiatal hernias deemed most at risk for recurrence. These include large paraesophageal hernias, recurrent hernias, overweight/obese patients, or older patients with scoliosis (23). Recurrence rates are indeed higher in the obese patient (27). Combined weight loss and hernia repair surgeries, including $\mathrm{PEH}$ repair with Roux-en-Y gastric bypass or sleeve gastrectomy, should be considered. However, the best approach in this patient population is not definitively answered in the current literature. Similarly, management controversies surround the re-operative $\mathrm{PEH}$ repair. While a standardized definition of PEH recurrence remains elusive, many consider repair in patients with radiographic recurrence of $>2 \mathrm{~cm}$ with worsening symptoms of dysphagia, reflux, and regurgitation (28). A thorough pre-operative work-up to include endoscopic evaluation, barium esophagram, and esophageal manometry should be performed, and surgical approach tailored to each individual patient's needs.

\section{Mesh materials}

As routine mesh reinforcement of the hiatus remains controversial, so too does the appropriate type of mesh material to be used. Generally, mesh materials may be classified as absorbable synthetic, permanent synthetic, or biologic (23). Non-absorbable PTFE meshes were the first explored as adjuncts to hiatal reinforcement, though the occurrence of erosions into the stomach or esophagus in some patients kept these from becoming standard (29). Absorbable meshes were introduced in an attempt to reduce the hernia recurrence rate without the associated morbidity of non-absorbable meshes. These may be biologic, including AlloDerm ${ }^{\circledR}$ (Allergan PLC, Dublin, Ireland), Surgisis ${ }^{\circledR}$ (Cook Medical, Bloomington, IN, United States), or synthetic, including Vicryl ${ }^{\circledR}$ (Ethicon, Somerville, NJ, United States) or Bio-A ${ }^{\circledR}$ (Gore Medical, Newark, DE, United States). While their safety over nonabsorbable meshes is often touted, long-term efficacy and cost effectiveness remains debatable.

Early systematic reviews have shown low recurrence rates between permanent, synthetic, and biologic mesh repairs (30,31). Watson and colleagues' prospective randomized trial compared suture cruroplasty and reinforced cruroplasty with absorbable mesh and nonabsorbable mesh in patients with large PEH (32). No differences in recurrence were observed between the three cohorts, though the study was limited to 12-month follow-up. Various suture patterns for primary suture cruroplasty have been proposed and include simple interrupted, figure-of- 8 , and pledgeted repair. At 24-month follow-up, quality-of-life was similar between groups. Various other randomized controlled trials and retrospective reviews have similarly evaluated biologic or multiple mesh materials with satisfactory outcomes with regard to preventing hiatal hernia recurrence (26,33-36).

Complications have been reported with all types of mesh, including esophageal stenosis, stricture, and mesh erosion, with more severe complications seemingly belonging to synthetic meshes (37). Because of these potential devastating complications, expert opinion has suggested mesh repair should be limited to biologically derived mesh for use only in large paraesophageal hernias or those presenting with recurrence (37). The ideal mesh material should assist in reinforcing crural repair without causing undue tension, erosion, or dysphagia, combined with longterm durability. Unfortunately, the ideal mesh material has yet to be realized. Consequently, the Society of American Gastrointestinal Endoscopic Surgeons (SAGES) guidelines conclude there is insufficient evidence to support for or against the use of mesh for crural reinforcement (3).

\section{Mesh configuration}

The correct configuration of mesh is also controversial. 
The most commonly used arrangements include U-shaped, rectangle, reverse C-shaped, and keyhole (37). It has been previously reported that recurrent hiatal hernia defects tend to occur anteriorly and to the left of the esophagus and be more circular in shape, suggesting the defects may be related to progression of disease rather than failure of the previous repair (38). Therefore, the authors have favored a transition from a U-shaped configuration to a keyhole or "reverse C" arrangement as to circumferentially buttress the tensile strength of the hiatus. This configuration has been supported by previously reported series utilizing a keyhole approach with low recurrence rates when compared to primary repair $(39,40)$. Currently, however, insufficient long-term evidence exists to recommend one mesh configuration over another. Regardless of favored technique, it is recommended the configuration of the mesh allow for reinforcement of the anterior hiatus and to the left of the esophagus, as this is where most recurrences have been observed.

\section{Need and type of fundoplication}

Regardless of hiatal hernia type, a fundoplication should be routinely performed with few exceptions. Fundoplication increases the resting pressure of the lower esophageal sphincter, addresses pre-operative gastroesophageal reflux in the case of sliding hiatal hernias, prevents reflux postoperatively due to extensive hiatal dissection, and serves as a gastropexy to ensure the stomach lies below the diaphragm (41). The vast majority of patients should undergo characterization of their esophageal motility prior to anti-reflux surgery by way of high-resolution manometry. In the absence of pre-operative symptoms or confirmatory testing, the authors routinely perform a complete 360-degree fundoplication (laparoscopic Nissen fundoplication). In cases of pre-operative dysphagia, or confirmed ineffective esophageal motility, a partial posterior 240-degree fundoplication (Toupet fundoplication) is utilized (41).

In the 1960s and 1970s, Nissen fundoplications were often done over small dilators with fundoplications up to 6 centimeters (23). Patients often complained of dysphagia and bloating, and as a consequence, the Nissen fundoplication became known colloquially to turn "belchers into bloaters". In attempts to mitigate these side effects, various innovative surgical techniques were developed, giving rise to the Toupet, Dor, Gaurner, and Watson partial fundoplications (23). However, these approaches have been recognized to result in higher rates of recurrent symptoms, likely secondary to eventual disruption of the fundoplication (42). The introduction of the "short, floppy" Nissen, especially in the era of laparoscopy, allowed for more widespread adoption and rapidly became the workhorse in anti-reflux surgery. Since Dellamagne and colleagues' first description of laparoscopic Nissen fundoplication, the technique has become the predominant approach in those with appropriate esophageal motility (43).

\section{Magnetic sphincter augmentation}

While Nissen fundoplication has become standardized, it remains a nuanced operation with poor symptom relief and outcomes if performed inadequately. Even in the perfectly performed operation, several studies suggest long term symptom recurrence and the need for resumption of proton pump inhibitor therapy following anti-reflux surgery (44). Magnetic sphincter augmentation, particularly with the Lin $x^{\circledR}$ device, has sought to standardize anti-reflux surgery and provide durable results. Despite the lack of randomized trial data, magnetic sphincter augmentation continues to grow in popularity.

Early reports suggest effectiveness in reducing pathologic reflux with low risk of side effects. Symptomatic dysphagia, despite occurring in $6 \%$ to $83 \%$ of patients, only requires esophageal dilation in $8 \%$ (45). Device erosion also appears a rare occurrence, reported in only $0.03 \%$ in patients (45). Device durability appears significant with magnetism lasting in the hundreds of years.

The role of magnetic sphincter augmentation in paraesophageal hernia repair should likely be limited based on individual patient considerations. Those with symptomatic GERD with appropriate esophageal motility undergoing paraesophageal hernia repair should be considered for sphincter augmentation in an effort to improve pathologic reflux. Though there are limited data in this patient cohort, the benefit extrapolated from numerous studies demonstrating its effectiveness in reducing GERD symptoms cannot be understated.

\section{Gastropexy}

The placement of a gastrostomy tube may be used to provide enteral feeding access, post-operative venting in cases of delayed gastric emptying, as well as provide fixation of the anterior stomach to the abdominal wall (3). Hernia reduction with gastropexy alone without concomitant hiatal 
hernia repair may be an alternative approach in patients deemed high-risk but is associated with higher recurrence rates and thus, formal repair is preferred (46). While morbidity and mortality were low in a limited series by Rosenberg and colleagues, radiologic recurrence rate was $14 \%$ at 3 months (47). Results are inferior to formal repair techniques described herein. In general, gastropexy should be reserved for extreme cases and approached as a fallback option rather than an upfront durable repair. The authors recommend gastropexy in the emergent or urgent setting to assist in the reduction of a stomach that has volvulized, and do not recommend gastropexy in the elective setting when the stomach can be delivered to the abdomen without tension.

\section{Summary}

Paraesophageal hernia repair remains a staple in the armamentarium of the foregut surgeon. Current literature suggests paraesophageal hernia repair should be approached in a patient-centered, precision medicine manner. In general, hernia reduction, sac excision, and primary suture approximation of the hiatal crura are mandatory. Use of mesh should be based on individual risk factors; if mesh is used, biological meshes appear to have a more favorable safety profile, with the "reverse C" or keyhole configuration allowing for increase in crural tensile strength at it most vulnerable areas. Use and choice of fundoplication or magnetic sphincter augmentation should be based on individual considerations. As technology and surgical technique advance, the long-term radiographic durability and symptom relief will likely markedly improve.

\section{Acknowledgments}

Funding: None.

\section{Footnote}

Reporting Checklist: The authors have completed the Narrative Review reporting checklist. Available at https:// dx.doi.org/10.21037/jtd-21-720

Peer Review File: Available at https://dx.doi.org/10.21037/ jtd-21-720

Conflicts of Interest: All authors have completed the ICMJE uniform disclosure form (available at https:// dx.doi.org/10.21037/jtd-21-720). VV reports speaking honoraria with Integra, consultant work with Innocoll, and proctorship honoraria with Johnson and Johnson. The other authors have no conflicts of interest to declare.

Ethical Statement: The authors are accountable for all aspects of the work in ensuring that questions related to the accuracy or integrity of any part of the work are appropriately investigated and resolved.

Open Access Statement: This is an Open Access article distributed in accordance with the Creative Commons Attribution-NonCommercial-NoDerivs 4.0 International License (CC BY-NC-ND 4.0), which permits the noncommercial replication and distribution of the article with the strict proviso that no changes or edits are made and the original work is properly cited (including links to both the formal publication through the relevant DOI and the license). See: https://creativecommons.org/licenses/by-nc-nd/4.0/.

\section{References}

1. Kahrilas PJ, Kim HC, Pandolfino JE. Approaches to the diagnosis and grading of hiatal hernia. Best Pract Res Clin Gastroenterol 2008;22:601-16.

2. Stylopoulos N, Gazelle GS, Rattner DW. Paraesophageal hernias: operation or observation? Ann Surg 2002;236:492500; discussion 500-1.

3. Kohn GP, Price RR, DeMeester SR, et al. Guidelines for the management of hiatal hernia. Surg Endosc 2013;27:4409-28.

4. Maziak DE, Todd TR, Pearson FG. Massive hiatus hernia: evaluation and surgical management. J Thorac Cardiovasc Surg 1998;115:53-60; discussion 61-2.

5. Fullum TM, Oyetunji TA, Ortega G, et al. Open versus laparoscopic hiatal hernia repair. JSLS 2013;17:23-9.

6. Luketich JD, Nason KS, Christie NA, et al. Outcomes after a decade of laparoscopic giant paraesophageal hernia repair. J Thorac Cardiovasc Surg 2010;139:395404, 404.e1.

7. Reinersman JM, Deb SJ. Transthoracic Paraesophageal Hernia Repair. Thorac Surg Clin 2019;29:437-46.

8. Mungo B, Molena D, Stem M, et al. Thirty-day outcomes of paraesophageal hernia repair using the NSQIP database: should laparoscopy be the standard of care? J Am Coll Surg 2014;219:229-36.

9. Zehetner J, Demeester SR, Ayazi S, et al. Laparoscopic versus open repair of paraesophageal hernia: the second 
decade. J Am Coll Surg 2011;212:813-20.

10. Nguyen NT, Christie C, Masoomi H, et al. Utilization and outcomes of laparoscopic versus open paraesophageal hernia repair. Am Surg 2011;77:1353-7.

11. O'Connor SC, Mallard M, Desai SS, et al. Robotic Versus Laparoscopic Approach to Hiatal Hernia Repair: Results After 7 Years of Robotic Experience. Am Surg 2020;86:1083-7.

12. Gerull WD, Cho D, Kuo I, et al. Robotic Approach to Paraesophageal Hernia Repair Results in Low LongTerm Recurrence Rate and Beneficial Patient-Centered Outcomes. J Am Coll Surg 2020;231:520-6.

13. Soliman BG, Nguyen DT, Chan EY, et al. Robot-assisted hiatal hernia repair demonstrates favorable short-term outcomes compared to laparoscopic hiatal hernia repair. Surg Endosc 2020;34:2495-502.

14. Watson DI, Davies N, Devitt PG, et al. Importance of dissection of the hernial sac in laparoscopic surgery for large hiatal hernias. Arch Surg 1999;134:1069-73.

15. Edye M, Salky B, Posner A, et al. Sac excision is essential to adequate laparoscopic repair of paraesophageal hernia. Surg Endosc 1998;12:1259-63.

16. Poncet G, Robert M, Roman S, et al. Laparoscopic repair of large hiatal hernia without prosthetic reinforcement: late results and relevance of anterior gastropexy. J Gastrointest Surg 2010;14:1910-6.

17. Leeder PC, Smith G, Dehn TC. Laparoscopic management of large paraesophageal hiatal hernia. Surg Endosc 2003;17:1372-5.

18. Hashemi M, Peters JH, DeMeester TR, et al. Laparoscopic repair of large type III hiatal hernia: objective followup reveals high recurrence rate. J Am Coll Surg 2000;190:553-60; discussion 560-1.

19. Mori T, Nagao G, Sugiyama M. Paraesophageal hernia repair. Ann Thorac Cardiovasc Surg 2012;18:297-305.

20. Greene CL, DeMeester SR, Zehetner J, et al. Diaphragmatic relaxing incisions during laparoscopic paraesophageal hernia repair. Surg Endosc 2013;27:4532-8.

21. Alicuben ET, Worrell SG, DeMeester SR. Impact of crural relaxing incisions, Collis gastroplasty, and non-cross-linked human dermal mesh crural reinforcement on early hiatal hernia recurrence rates. J Am Coll Surg 2014;219:988-92.

22. Mattar SG, Bowers SP, Galloway KD, et al. Long-term outcome of laparoscopic repair of paraesophageal hernia. Surg Endosc 2002;16:745-9.

23. Velanovich V. Practice-Changing Milestones in Anti-reflux and Hiatal Hernia Surgery: a Single Surgeon Perspective over 27 years and 1200 Operations. J Gastrointest Surg
2021. [Epub ahead of print]. doi: 10.1007/s11605-02104940-3.

24. Frantzides CT, Madan AK, Carlson MA, et al. A prospective, randomized trial of laparoscopic polytetrafluoroethylene (PTFE) patch repair vs simple cruroplasty for large hiatal hernia. Arch Surg 2002;137:649-52.

25. Granderath FA, Schweiger UM, Kamolz T, et al. Laparoscopic Nissen fundoplication with prosthetic hiatal closure reduces postoperative intrathoracic wrap herniation: preliminary results of a prospective randomized functional and clinical study. Arch Surg 2005;140:40-8.

26. Oelschlager BK, Pellegrini CA, Hunter J, et al. Biologic prosthesis reduces recurrence after laparoscopic paraesophageal hernia repair: a multicenter, prospective, randomized trial. Ann Surg 2006;244:481-90.

27. Morgenthal CB, Lin E, Shane MD, et al. Who will fail laparoscopic Nissen fundoplication? Preoperative prediction of long-term outcomes. Surg Endosc 2007;21:1978-84.

28. Holihan J, Felinski MM, Wilson TD, et al. Approach to the redo paraesophageal hernia. Annals of Laparoscopic and Endoscopic Surgery 2020. [Epub ahead of print]. doi: 10.21037/ales-2019-hh-05.

29. Quesada BM, Coturel AE. Use of absorbable meshes in laparoscopic paraesophageal hernia repair. World J Gastrointest Surg 2019;11:388-94.

30. Granderath FA, Carlson MA, Champion JK, et al. Prosthetic closure of the esophageal hiatus in large hiatal hernia repair and laparoscopic antireflux surgery. Surg Endosc 2006;20:367-79.

31. Antoniou SA, Pointner R, Granderath FA. Hiatal hernia repair with the use of biologic meshes: a literature review. Surg Laparosc Endosc Percutan Tech 2011;21:1-9.

32. Koetje JH, Irvine T, Thompson SK, et al. Quality of Life Following Repair of Large Hiatal Hernia is Improved but not Influenced by Use of Mesh: Results From a Randomized Controlled Trial. World J Surg 2015;39:1465-73.

33. Parsak CK, Erel S, Seydaoglu G, et al. Laparoscopic antireflux surgery with polyglactin (vicryl) mesh. Surg Laparosc Endosc Percutan Tech 2011;21:443-9.

34. Watson DI, Thompson SK, Devitt PG, et al. Laparoscopic repair of very large hiatus hernia with sutures versus absorbable mesh versus nonabsorbable mesh: a randomized controlled trial. Ann Surg 2015;261:282-9.

35. Tam V, Luketich JD, Levy RM, et al. Mesh cruroplasty in laparoscopic repair of paraesophageal hernias is not 
associated with better long-term outcomes compared to primary repair. Am J Surg 2017;214:651-6.

36. Lidor AO, Steele KE, Stem M, et al. Long-term quality of life and risk factors for recurrence after laparoscopic repair of paraesophageal hernia. JAMA Surg 2015;150:424-31.

37. Keville S, Rabach L, Saad AR, et al. Evolution From the U-shaped to Keyhole-shaped Mesh Configuration in the Repair of Paraesophageal and Recurrent Hiatal Hernia. Surg Laparosc Endosc Percutan Tech 2020;30:339-44.

38. Saad AR, Velanovich V. Anatomic Observation of Recurrent Hiatal Hernia: Recurrence or Disease Progression? J Am Coll Surg 2020;230:999-1007.

39. Zografakis J, Johnston G, Haas J, et al. Urinary Bladder Matrix Reinforcement for Laparoscopic Hiatal Hernia Repair. JSLS 2018;22:e2017.

40. Howell RS, Fazzari M, Petrone P, et al. Paraesophageal Hiatal Hernia Repair With Urinary Bladder Matrix Graft. JSLS 2018;22:e2017.

41. Serrano L, Saad AR, DuCoin C, Velanovich V. After the hiatal hernia repair: fundoplication, yes or no? Partial or complete? Ann Laparosc Endosc Surg 2021;6:22.

42. Horvath KD, Jobe BA, Herron DM, et al. Laparoscopic

Cite this article as: Rogers MP, Velanovich V, DuCoin C. Narrative review of manament controversies for paraesophageal hernia. J Thorac Dis 2021;13(7):4476-4483. doi: $10.21037 /$ jtd-21-720
Toupet fundoplication is an inadequate procedure for patients with severe reflux disease. J Gastrointest Surg 1999;3:583-91.

43. Dallemagne B, Weerts JM, Jehaes C, et al. Laparoscopic Nissen fundoplication: preliminary report. Surg Laparosc Endosc 1991;1:138-43.

44. Neuvonen P, Sand J, Matikainen M, et al. Does Nissen Fundoplication Provide Lifelong Reflux Control? Symptomatic Outcome After 31-33 Years. World J Surg 2017;41:2046-52.

45. Schizas D, Mastoraki A, Papoutsi E, et al. LINX® reflux management system to bridge the "treatment gap" in gastroesophageal reflux disease: A systematic review of 35 studies. World J Clin Cases 2020;8:294-305.

46. Agwunobi AO, Bancewicz J, Attwood SE. Simple laparoscopic gastropexy as the initial treatment of paraoesophageal hiatal hernia. Br J Surg 1998;85:604-6.

47. Rosenberg J, Jacobsen B, Fischer A. Fast-track giant paraoesophageal hernia repair using a simplified laparoscopic technique. Langenbecks Arch Surg 2006;391:38-42. 